\title{
Revisão integrativa sobre a prática infracional na adolescência (2005/2014)
}

Luciene Jimenez. Universidade Anhanguera de São Paulo.

Vanda Regina Marques. Prefeitura do Município de Diadema.

\section{Resumo}

Revisão integrativa de 39 artigos publicados entre os anos 2005/2014 visando identificar a compreensão dos pesquisadores brasileiros sobre os fatores implicados na prática infracional na adolescência. Predominaram pesquisadores e periódicos das áreas da psicologia e da saúde, e pesquisas qualitativas com adolescentes em privação de liberdade. Para a análise foram construídas oito categorias que deram origem a três grupos discursivos. O primeiro grupo identificou as razões presentes no dia-a-dia dos adolescentes que vivem nas periferias. O segundo atentou para a história de vida, com presença de violências e privações associadas à falta de oportunidade e ao imperativo de uma sociedade consumista. $O$ terceiro grupo problematizou os mecanismos sociais de identificação de determinados grupos como desviantes por meio dos discursos institucionalizados. Desde a perspectiva do interacionismo simbólico, propõe-se uma compreensão histórico política do desvio enquanto produção coletiva. Palavras chave: revisão de literatura; adolescente em conflito com a lei; delinquência juvenil.

\section{Abstract}

Integrative review about the practice of illegal acts in adolescence (2005/2014). Integrative review of 39 articles published between the years 2005/2014 aimed at identifying the understanding of Brazilian researchers on the factors involved in criminal behavior in adolescence. In analyzed articles predominate researchers and journals from the fields of psychology and health, and qualitative research with adolescents deprived of freedom. For analyzing eight categories were constructed that source three discourse groups on the reasons for deviant behavior. The first group identified the reasons present in day-by-day of teenagers living in the outskirts. The second group looked at the history of life of adolescents: abandonment of experiences, violence and deprivations associated with poverty, lack of opportunity and to imperative of a consumer and immediatist society. The third group problematized the socials mechanisms of identification of certain groups as deviant through discourses institutionalized. It is proposed as historic understanding of collective production, from the perspective of symbolic interaction.

Keywords: literature review; teenager in conflict with the law; juvenile delinquency.

\section{Resumen}

Revisión integradora acerca de la conducta delictiva en la adolescencia (2005/2014). Revisión integradora de 39 artículos publicados entre los años 2005/2014 destinada a la identificación de la comprensión de los investigadores brasileños acerca de los factores que intervienen en la conducta delictiva. Predominan revistas e investigadores de las áreas de la psicología y la salud, e investigación cualitativa con adolescentes que cumplían medida-socioeducativa en régimen cerrado. Para el análisis sobre los motivos de la conducta criminal fueran creadas ocho categorías que originaran tres grupos discursivos. El primer grupo identificó los motivos presentes en el día a día de la vida de los adolescentes. El segundo, identificó la historia de vida y las experiencias de violencias asociadas con la pobreza, y el imperativo de una sociedad consumista e inmediatista. El tercer grupo problematizó los mecanismos sociales de identificación de los desviantes. Desde la perspectiva del interaccionismo simbólico apuntase para la comprensión política de la desviación como una producción colectiva.

Palabras clave: revisión de literatura; adolescente en conflicto con la ley; delincuencia juvenil. 
A expressão "adolescente em conflito com a lei" foi cunhada a partir do Estatuto da Criança e do Adolescente - ECA (Lei n. 8.069, 1990) e remete aos adolescentes aos quais se atribui a prática infracional, conduta equiparada a crime ou contravenção penal praticada por adolescentes entre 12 anos completos e 18 anos incompletos. Mediante tais circunstâncias, os adolescentes podem estar sujeitos às medidas socioeducativas - MSE (Lei n. 8.069, 1990). Existem seis medidas socioeducativas, sendo a mais severa a internação, seguida da semiliberdade. As medidas socioeducativas em meio aberto são quatro, sendo que, duas delas advertência e obrigação de reparar o dano - se esgotam no âmbito do judiciário e as outras duas consistem em prestação de serviços à comunidade - PSC - liberdade assistida - LA (Lei n. 8.069, 1990).

O total de adolescentes em cumprimento de medida dentro de unidades de internação ou de semiliberdade em 2014 foi de 24.628, e o número de adolescentes em cumprimento de medida socioeducativa em meio aberto (LA/PSC) no mesmo ano foi de 67.356, somando 91.984 adolescentes brasileiros em cumprimento de alguma medida socioeducativa (excluindo reparação de danos e advertência, cujos números são desconhecidos) (Ministério dos Direitos Humanos, 2017).

Os atos infracionais mais frequentes são contra a propriedade, e o perfil destes adolescentes tem se mantido no decorrer dos anos, incidindo sobre o sexo masculino, cor parda/negra, evadidos do sistema formal de ensino, que vivem com famílias na faixa da pobreza (Ministério dos Direitos Humanos, 2017).

Para a execução de tais medidas é prevista a contratação de profissionais identificados como "equipe técnica", socioeducadores ou orientadores que provêm de diferentes formações acadêmicas, pois a equipe deve ser interdisciplinar (Ministério dos Direitos Humanos, 2012).

A complexidade da temática aliada à importância de oferecer subsídios, em particular aos profissionais que trabalham com estes adolescentes, seja em situação de internação ou em meio aberto, motivou a realização deste trabalho que teve como objetivo realizar um levantamento bibliográfico voltado para identificar como os pesquisadores brasileiros estão compreendendo a prática infracional.

\section{Método}

Elegeu-se a revisão integrativa que permite que sejam analisados estudos com diferentes delineamentos metodológicos, tendo como compromisso sistematizar os conhecimentos de modo que estes possam subsidiar a prática profissional, promovendo a possibilidade de aplicação dos achados das pesquisas na prática cotidiana (Botelho, Cunha, \& Macedo, 2011). Os autores sugerem cinco etapas: 1) Definição do problema e formulação de uma pergunta de pesquisa, definindo-se descritores e estratégias de busca; 2) estabelecimento dos critérios de inclusão e exclusão dos trabalhos a serem analisados; 3) Identificação dos estudos pré-selecionados e selecionados; 4) Categorização dos estudos selecionados; 5) Análise e interpretação dos resultados.

A pergunta norteadora do presente trabalho remete a quais são os postulados dos pesquisadores brasileiros sobre os motivos ou fatores envolvidos na prática infracional. A coleta dos artigos se deu entre novembro de 2014 a janeiro de 2015 nas bases SciELO, PePSIC, PsycINFO, BVS, Lilacs com auxílio do google alert. A busca foi simples por meio dos descritores: delinquência juvenil, ato infracional, adolescente em conflito com a lei, medidas socioeducativas, liberdade assistida, prestação de serviços à comunidade.

Optou-se por excluir os trabalhos que não abordassem os fatores implicados na infracionalidade, o que resultou em 21 exclusões, a maioria referente ao processo socioeducativo e sete artigos de revisão. Foram incluídos artigos publicados entre os anos $2005 / 2014$, produzidos por pesquisadores brasileiros e sobre a realidade nacional que apresentaram dados primários ou reflexões teóricas sobre os fatores implicados na prática infracional. Uma exceção foi o estudo de Ferreira (2007) que comparou o perfil dos adolescentes em cumprimento de medida socioeducativa nos Estados Unidos e no Brasil, agregando algumas informações sobre aquele país.

Foram selecionados 39 artigos (Bastos \& Rabinovich, 2012; Bocca, 2009; Branco, Wagner, \& Demarchi, 2008; Brito, 2007; Carvalho \& Gomide, 2005; Castro \& Guareschi, 2008; Dell'Ágllio, Benetti, Deretti, D'Incao, \& Leon, 2005; Dias, Arpini, \& Simon, 2011; Feitosa \& Boarini, 2014; Ferreira, 2007; Formiga, 2010; Francisco \& Martins, 2014; Gallo \& Williams, 2008; Gomes \& Conceição, 2014; Huculak, Mclennan, \& Bordin, 2011; I. R. O. Silva \& Salles, 2011; Junqueira \& Jacoby, 2006; Lazzarotto, 2014; Lima, Alcântara, Almeida, \& Alves, 2006; Maraschin \& Raniere, 2011; Moreira \& Toneli, 2014; Muller, Barbosa, Oliveira, Santos, \& Paludo, 2009; Nardi \& Dell'Aglio, 2012; Priuli \& Moraes, 2007; Schmitt, Pinto, Gomes, Quevedo, \&

Estudos de Psicologia, 23(2), abril a junho de 2018, 111-121 
Stein, 2006; M. M. C. Silva, 2007; M. M. C. Silva, 2009; Souza, Silva-Abrão \& Oliveira-Almeida, 2011; Spagnol, 2005; Vorcaro, Mazzini, \& Monteiro, 2008; Zappe \& Dias, 2012a; Zappe \& Ramos, 2010) dos quais sete eram específicos sobre a relação entre a prática infracional e as drogas (Bernardy \& Oliveira, 2010; Conte, Henn, Oliveira, \& Wolff, 2008; Lühring et al., 2014; Martins \& Pillon, 2008; Pereira \& Sudbrack, 2008; Valença \& Castro, 2014; Zappe \& Dias, 2012b).

A partir da identificação e seleção do material foram realizadas duas etapas subsequentes voltadas para a análise. A primeira etapa categorizou os artigos selecionados a partir de um instrumental em formato de tabela na qual foram identificados o ano de publicação do artigo, o periódico, a área de concentração dos periódicos, a formação do primeiro autor, o método, o campo, os participantes e os principais achados.

Este tipo de instrumental é chamado de matriz de síntese, ou matriz de análise e tem sido utilizado como ferramenta de extração, organização e interpretação de dados de revisão da literatura em várias disciplinas (Kolpper, Lubbe, \& Rugbber, 2007 citados por Botelho, Cunha, \& Macedo, 2011).

A segunda etapa resultou da leitura interpretativa dos resultados das pesquisas. Para os estudos empíricos foram construídas oito categorias de análise e os estudos teóricos foram analisados a parte.

\section{Análise}

As áreas de conhecimento abarcadas pelos periódicos foram identificadas no portal das revistas e agrupadas de acordo com a classificação de áreas do conhecimento da Coordenação de Aperfeiçoamento de Pessoal de Nível Superior - CAPES ${ }^{1}$. Foi identificada uma concentração de artigos publicados em revistas da Grande Área das Ciências Humanas, totalizando 28 trabalhos, ou seja, $71,8 \%$ das publicações; entre estes chama a atenção o fato de 21 (53,8\%) serem da Área Básica da Psicologia. A seguir, predominam os periódicos da Grande Área das Ciências da Saúde, com sete artigos (18\%). Da Grande Área das Ciências Sociais Aplicadas foram encontrados apenas quatro artigos (10,25\%).

Para analisar a formação do primeiro autor considerou-se a primeira graduação, cuja informação foi obtida por meio de consulta ao Currículo Lattes, obtendo-se os seguintes resultados: 30 (77\%) de autores da Grande Área das Ciências Humanas, sendo 24 (61,6\%) de psicólogos. Cinco autores (12,8\%) são da Grande
Área das Ciências da Saúde e quatro autores (10,2\%) são Da Grande Área das Ciências Sociais Aplicadas.

\section{Participantes dos Estudos}

Os participantes das pesquisas foram na sua maioria adolescente ( 22 estudos, 56,4\%), destes, 15 do sexo masculino, um do sexo feminino e três estudos com adolescentes de ambos os sexos. Duas pesquisas foram realizadas com jovens do sexo masculino pertencentes à classe média, e duas com adolescentes reincidentes. Dois estudos incluíram também profissionais de unidades de internação ou escola e outros dois agregaram informações obtidas em prontuários ou processos. Em seguida predominam os estudos com familiares (três). Os estudos documentais abarcaram análise de prontuários (dois), de processos (um), de sentenças (dois), de acórdãos (um) e os documentos foram obtidos por diferentes meios de acesso.

\section{Campos das Pesquisas}

As Unidades de Internação foram privilegiadas como campo, pois $18(46,15 \%)$ estudos se desenvolveram nestes espaços. A seguir, os campos mais pesquisados foram: os serviços que executam medidas em meio aberto (nove pesquisas), escolas (duas) e uma pesquisa realizada em cada um dos locais a seguir: Fórum, tribunal de justiça, vara da infância, conselho tutelar, unidade de semiliberdade.

\section{Métodos}

Predominaram os estudos empíricos, sendo o método qualitativo utilizado em 23 estudos (59\%), o quantitativo em 11 (28\%) e o quantiqualitativo em dois. Três estudos foram teóricos. Tais achados são consonantes com os dados encontrados por Zappe e Dias (2010) que indicam a tendência brasileira de pesquisa empírica sobre o adolescente autor de ato infracional, sendo o método qualitativo o mais utilizado.

\section{Análise dos estudos empíricos}

Para a análise dos estudos empíricos foram construídas oito categorias identificadas e elaboradas a partir das considerações dos pesquisadores, são elas: perfil dos adolescentes, classe social, família, escola, violência, drogas, discursos institucionais, subjetividade. Tal análise deve considerar os achados da análise estrutural que identificou os adolescentes do sexo masculino internados como participantes da maioria das pesquisas. Os estudos teóricos foram analisados a parte. 


\section{Perfil dos Adolescentes, Classe Social e Família}

Os adolescentes tinham entre 15 e 18 anos, embora Zappe e Ramos (2010) tenham identificado um adolescente de 11 anos internado, o que configura grave desrespeito ao ECA (Lei n. 8.069, 1990). A maioria dos participantes das pesquisas que originaram os artigos é pertencente aos estratos mais pobres da população. A relação entre pobreza e desvio é histórica, embora adolescentes de classe média também possam se envolver na prática infracional.

Segundo Spagnol (2005), não há estudos sobre a delinquência entre os jovens pertencentes às classes média e média alta. Entretanto, essa delinquência existe, mas as informações não chegam a público e seus familiares entram em cena imediatamente para que não haja a menor possibilidade de o adolescente ingressar na Febem como infrator. A mídia também colabora. As notícias que geram maiores polêmicas são as de crimes praticados por adolescentes oriundos da periferia (p. 277).

Nos Estados Unidos, onde a seletividade do sistema de justiça talvez funcione de forma diferente do Brasil, a maioria dos adolescentes que infracionaram se identifica como pertencente à classe média (Ferreira, 2007/2008). A seletividade é difícil de ser estudada, pois pode ocorrer no momento da abordagem policial, quando se decide pela apreensão ou não do jovem, até o momento do julgamento, quando adolescentes de classes abastadas tenderão a receber um tratamento diferenciado, sendo encaminhado para acompanhamento psicológico, recebendo medidas socioeducativas consideradas mais amenas, como a advertência ou a reparação de danos, ou outros procedimentos que não resultam no cumprimento de medidas socioeducativas.

A presença da seletividade pode explicar, ainda que parcialmente, o perfil dos adolescentes encontrado no presente estudo de revisão. A realidade das famílias é precária, com baixo nível de renda, de escolaridade e abuso de álcool ou drogas. A maioria vivia com as mães ou avós, as mães eram as provedoras do lar e a principal figura na internação, além de mediadora entre o adolescente, o poder judiciário e a comunidade, a maioria tem ou teve familiares presos ou envolvidos com drogas (Bernardy \& Oliveira, 2010; Dias et al., 2011; Francisco \& Martins, 2014; Muller et al., 2009; Priuli \& Moraes, 2007; I. R. O Silva \& Salles, 2011; Souza et al., 2011; Zappe \& Ramos, 2010). As práticas parentais indicam a presença de conflitos, distanciamentos e disciplina relaxada, ou seja, os pais evitam colocar limites e estabelecer contingências (Carvalho \& Gomide, 2005; Nardi \& Dell'Áglio, 2012). As próprias mães relacionam o ato infracional aos problemas com a figura paterna (ausência ou conflito) e se sentem culpadas pelo ato infracional, não questionando os fatores sociais (Dias et al., 2011).

Alguns autores buscam transcender a noção de família "desestruturada" relacionando tal noção ao ideário higienista, como instrumento privilegiado para o exercício do controle, donde a importância delegada ao pai. A ideologia higienista, surgida no final do século XVIII, postulou que a doença tinha entre suas origens os hábitos de vida das populações, tais como: a ociosidade, o desregramento sexual, a desorganização familiar etc. (Oliveira Sobrinho, 2013). A ausência paterna constitui uma temática a ser problematizada quando se reflete sobre os adolescentes em conflito com a lei, pois é questionavel se tal ausencia tem relação direta com os comportamentos infracionais, ou se os mesmos estão inseridos em um bojo complexo de causalidades, dentre elas os fatores sociais e econômicos.

\section{Escola, Violência e Drogas}

A maioria dos adolescentes possuía ensino fundamental incompleto, se encontrava evadido do sistema formal de ensino (Muller et al., 2009; I. R. O. Silva \& Salles, 2011; Souza et al., 2011; Zappe \& Ramos, 2010). Não frequentar a escola foi associado a um número crescente de reincidências, ao uso de entorpecentes e, também, ao emprego de armas (Gallo \& Williams, 2008). A despeito da importância deste espaço, os profissionais tendem a se mostrar ambíguos com relação aos adolescentes em conflito com a lei: ao mesmo tempo em que reconhecem suas responsabilidades como educadores, admitem a existência de exclusão no ambiente escolar (I. R. O. Silva \& Salles, 2011). Devido às dificuldades de estabelecer vínculos com a escola $\mathrm{e}$ com atividades de trabalho, a rede social tende a ficar empobrecida, restringindo as relações sociais à família e aos amigos (Branco et al., 2008).

A maioria dos adolescentes refere já ter experimentado algum tipo de violência. Lima et al. (2006) identificaram que $92 \%$ dos adolescentes já haviam experimentado, pelo menos uma vez na vida, algum tipo de violência no ambiente familiar sendo as mais comuns: ameaças de lesão física, ter sido espancado ou assaltado e/ou baleado, abandono, dormir na rua, surras, golpes na cabeça, emprego de palmatórias, beliscões e pontas-pé, além de mordidas ou ataques provocados por cães (Huculak et al., 2011; Lima et al., 2006). Embora as altas

Estudos de Psicologia, 23(2), abril a junho de 2018, 111-121 
taxas de exposição à violência tenham sido semelhantes para adolescentes de ambos os sexos (Huculak et al., 2011), as meninas relatam também gravidez, aborto e violência sexual, chegando a um índice de $34 \%$ de relatos de abuso sexual (Dell'Ágllio et al., 2005).

Além da violência familiar, os adolescentes pesquisados vivem em regiões precárias, fortemente marcadas pela presença de criminalidade e do tráfico de drogas (Zappe \& Dias, 2012a). Ainda são frequentes os relatos de violência policial no momento da apreensão, na delegacia e durante a internação (Francisco \& Martins, 2014).

A relação entre a prática infracional e o uso de drogas é polêmica. É frequente que os adolescentes pesquisados relatem uso de drogas (Priuli \& Moraes, 2007), bem como o uso de algumas drogas, tais como álcool e maconha, podem aparecer associados à primeira prática infracional, embora outras drogas, como cocaína, não tenham mostrado a mesma relação. (Martins \& Pillon, 2008). Lühring et al. (2014) identificou que $60,5 \%$ dos adolescentes relatou não relacionar o ato infracional com as drogas, mas a análise quantitativa da pesquisa mostrou o contrário. Muller et al. (2009) identificaram que $66 \%$ das infrações cometidas eram contra o patrimônio, 34\% dos adolescentes referiram que as mesmas foram para subsistência e apenas $22 \%$ para uso de drogas.

Pereira e Sudbrack (2008) chamam a atenção para a complexidade do fenômeno, pois entre o adolescente e a droga existem outras relações. Pode haver o delito em função da abstinência da droga, ou, ao contrário, há o uso de drogas para ter coragem para cometer o delito, ou ainda, a droga pode ser utilizada como álibi etc. As autoras descontroem a relação unívoca entre ato infracional e uso de drogas. Neste mesmo sentido, Conte et al. (2008) atentam para a relação estereotipada de causa e efeito entre uso de drogas e prática infracional.

A controvérsia que cerca a temática "drogas" inclui a participação no tráfico de drogas, pois foram encontrados índices de participação que variaram de 0,9\%, (Zappe \& Ramos, 2010), 58,8\% (Fracisco \& Martins, 2014) até 74\% (Martins \& Pillon, 2008). A amplitude de tal variação $(0,9 \%$ a $74 \%)$ sugere que a relação entre a prática infracional e o tráfico de drogas não é óbvia e carece de reflexão. A Súmula 492 do Supremo Tribunal de Justiça afirma que "O ato infracional análogo ao tráfico de drogas, por si só, não conduz obrigatoriamente à imposição de medida socioeducativa de internação do adolescente" (Supremo
Tribunal de Justiça, 2012). A Convenção 182 de 1999 da Organização Internacional do Trabalho reconhece o tráfico de drogas não como um delito, mas dentre as piores formas de trabalho na infância, e na sua Recomendação 190 sugere ações para a erradicação de tal atividade. A Convenção e sua Recomendação foram ratificadas pelo governo brasileiro no Decreto no. 3.597, de 12 de setembro de 2000 (Decreto no 3.597, 2000). A compreensão de que o tráfico de drogas não constitui um ato infracional, inclusive pelo fato de não ser cometido mediante grave ameaça ou violência, mas antes são decorrentes da demanda daqueles que buscam o traficante, é polêmica. A decisão mediante tais situações tende a ser variável dependendo da compreensão de cada juiz. Tal fato explica, ainda que parcialmente, a extrema variação na porcentagem de adolescentes (0,9\% a $74 \%)$ em cumprimento de medida socioeducativa devido ao envolvimento com o tráfico.

Não obstante, o uso de drogas constou entre os principais motivos identificados em sentenças para a internação de adolescentes (Feitosa \& Boarini, 2014; Zappe \& Ramos, 2010). No Brasil, o uso de drogas não é criminalizado e os adolescentes usuários deveriam ser encaminhados para acolhimento nos serviços de saúde mental. No entanto, como veremos a seguir, a internação em unidade socioeducativa tem sido utilizada como recurso para tratamentos diversos.

\section{Discursos Institucionais}

Partindo da análise de sentenças, a internação tende a ser vista pelos juízes como tratamento e cura, situação capaz de proteger o adolescente da família "desestruturada" e a sociedade do adolescente, bem como um espaço capaz de dar educação intensiva e preparar para o trabalho (Feitosa \& Boarini, 2014). A conjunção de alguns elementos como: uso de drogas, desestruturação familiar, social e escolar compõe o que Valença e Castro (2014) chamaram de "carreiras de indisciplina", terá grande possibilidade de resultar em internação. Os discursos institucionais presentes nos processos judiciais apontam para uma ideia de adolescentes portadores de um difícil prognóstico, irrecuperáveis, de comportamento agressivo e desafiador e produzem, muitas vezes, o agravamento da situação do adolescente e a determinação da privação de liberdade. É exemplar desta constatação a fala de um dos adolescentes entrevistado por Castro e Guareschi (2008) ao se referir ao conteúdo do relatório de uma profissional da unidade de internação: "se essa mulher acha que eu não mudei, então eu não vou nunca muda (sic) mesmo". 
Esta dinâmica faz com que o adolescente se mostre desinteressado, desconfiado e com ressentimento de ser considerado drogado e rebelde (Souza et al., 2011). No entanto, o estudo de M. M. C. Silva (2009) estudou processos de adolescentes do sexo feminino e reconheceu que, independentemente do ato infracional cometido, se as adolescentes argumentassem de forma ajustada às convenções, ou seja, submissão e obediência à autoridade dos pais, responsabilidade com os estudos e preocupação com o futuro, recebiam medidas socioeducativas mais brandas e pareceres menos acusatórios.

\section{Subjetividade}

Os próprios adolescentes identificam como motivos para o envolvimento infracional a facilidade para entrar para o tráfico de drogas, a vida na comunidade, a influência dos amigos, as relações familiares e escolares problemáticas, o desejo de ter dinheiro para gastar com drogas, festas e mulheres, o desejo de visibilidade, pertencimento e prestígio (Gomes \& Conceição, 2014; Junqueira \& Jacoby, 2006, I. R. O. Silva \& Salles, 2011). Entre os fatores que podem levar ao abandono de tais práticas foram identificados o envolvimento amoroso (namorar), ter uma religião e a decepção com amigos (Gomes \& Conceição, 2014).

As condutas desviantes foram compreendidas pelos autores desde diferentes perspectivas. A partir de características psíquicas particulares que podem, inclusive, indicar a prevalência aumentada de personalidade psicopática entre os adolescentes autores de crimes contra a vida (Schmitt et al., 2006), ou, como um reflexo da debilidade dos limites convencionais (Formiga, 2010). Por meio do ato infracional, os adolescentes podem estar expressando o "mal-estar" de suas experiências de abandono físico e afetivo, seus desassossegos e angústias, o preconceito vivido e a falta de oportunidade em meio à sociedade; ou seja, o ápice de várias e sucessivas privações (Bocca, 2009; Castro \& Guareschi, 2008).

Com relação aos adolescentes pertencentes à classe média, Spagnol (2005) assinala que, para os jovens entrevistados por ele, levar o fruto do roubo não era tão importante quanto humilhar o outro durante a ação, há uma qualidade sedutora da ação ilícita que é a busca da emoção, fato ausente dentre os adultos. Já para os jovens da classe média, além da emoção há a imitação "dos jovens da periferia, identificando-se com as roupas, a linguagem, o gestual "[...]. Para os jovens de classe média ser tachado de marginal pelos outros chega a ser uma conquista" (Spagnol, 2005, p. 288). Para Bastos e Rabinovich (2012), o alongamento da juventude, o aumento de anos de estudo e de moradia com os pais, ocasiona uma falta de responsabilização pelos atos cometidos pelos jovens pertencentes às classes sociais mais abastadas, criando situações facilitadoras para a transgressão.

A indústria do consumo e da mídia, as características da sociedade contemporânea que primam pelo consumo e pelo imediatismo, a mudança na configuração familiar, com o enfraquecimento da autoridade paterna faz com que jovens das diversas classes sociais busquem referenciais de autoridade e pertencimento em ambientes externos (Bastos \& Rabinovich, 2012; Spagnol, 2005; Zappe \& Dias, 2012b).

Por outro lado, há ainda que se considerar a possibilidade de uma relação inversa, ou seja, a conduta desviante não deve ser personalizada neste ou naquele sujeito, mas antes, deve ser compreendida como efeito dos discursos produzidos nos micro espaços, que incluem profissionais e juristas. Para Lazzarotto (2014) há aí um jogo de circunstâncias de um determinado momento histórico que atrai sobre determinado indivíduo, seus equívocos e suas condutas, o olhar do poder e seus mecanismos de vigilância, focando este indivíduo de preferência àquele. M. M. C. Silva (2007) alerta para o fato de que o processo de aplicação das medidas socioeducativas legitima os estereótipos sobre a "delinquência juvenil" encontrados no senso comum. A autora inspira-se na ideia de produção da delinquência trabalhada por Michel Foucault, na qual a biografia do indivíduo, neste caso o adolescente, é desmembrada, simplificada, analisada e descrita, possibilitando desta forma uma ligação quase "natural" à atitude infratora.

\section{Análise dos estudos teóricos}

Maraschin e Raniere (2011) problematizaram a atual dimensão legal da execução da medida socioeducativa, chamando a atenção para o fato de que, independentemente de estar amarrada "a um caráter punitivo, reeducativo, restaurativo, protagonista, garantista, só funciona quando acoplada a este difuso de vários nomes: psique, personalidade, identidade, individualidade" (p. 97). Os vários nomes revelam que o processo socioeducativo está centrado em uma suposta essência individual do adolescente, e exemplificam citando que o principal instrumento de trabalho utilizado pelos socioeducadores é intitulado Plano Individual de 
Atendimento (PIA). A noção de indivíduo, a crença na existência de um "eu", independentemente de ser um "eu" inato ou socialmente construído, assume centralidade no exercício da dominação/domesticação da vida. Os autores ainda questionam se o Sistema Nacional de Atendimento Socioeducativo - Sinase - (Conselho Nacional dos Direitos da Criança e do Adolescente [CONANDA], 2006), documento norteador da política socioeducativa, não seria a radicalização de um processo de regulação/dominação sobre o adolescente infrator iniciado há quase 100 anos. Compreendida desta maneira, a proposta legal vigente no Brasil corre o risco de ser a reificação do paradigma correcional, no qual o adolescente era tratado como objeto de tutela do estado, negligenciando-se o contexto social e cultural no qual está inserido.

Neste mesmo sentido, Brito (2007), reflete especificamente sobre a medida de liberdade assistida, identificando que procedimentos semelhantes já estavam presentes desde o século XIX por meio de ações filantrópicas. Naquele momento, compreendia-se que os infratores eram portadores de defeitos morais, ou patologias, devendo por isso comparecer regularmente a uma instituição para serem acompanhados por um orientador, quando então, deveriam comprovar que estavam trabalhando e/ou estudando. Posteriormente, no Código de Menores de 1927, os mesmos procedimentos foram chamados de "liberdade vigiada", e, por fim, de liberdade assistida no Código de 1979, nome que permaneceu no ECA. A autora alerta para o fato de que, apesar do paradigma garantista do ECA, que objetiva garantir direitos aos adolescentes compreendendo-os como sujeitos, o histórico coercitivo da medida de liberdade assistida corre o risco de se perpetuar, individualizando o comportamento transgressor e, até mesmo, patologizando.

A temática da patologização emergiu também do estudo de Vorcaro et al. (2008), os autores alertam para "a atribuição indiscriminada da falta de um pai concreto como causa de delitos de adolescentes" (p. 135). Sem negar a importância da história do indivíduo para a constituição da subjetividade, os autores enfatizam que experiências semelhantes, como a ausência de um pai, podem ser elaboradas de formas distintas pelos sujeitos. $\mathrm{O}$ ato infracional pode ser compreendido não como a expressão de uma falta específica, mas como tentativa, mesmo que malograda, de fazer laço social. Diante da ausência violenta de quase tudo que seria de direito, o crime aparece ao adolescente como meio instantâneo pelo qual ele constitui uma identidade entre os iguais, na sua comunidade, e também na sociedade de modo geral, ainda que seja uma identidade negativa (Vorcaro et al., 2008, p. 139).

Os autores alertam para o fato de que é necessário muito cuidado ao transpor conceitos psicanalíticos para o campo social.

\section{Discussão}

A prática infracional na adolescência, embora estudada predominantemente por profissionais da psicologia e das ciências da saúde, dispõe de um repertório teórico variado. A predominância de pesquisas qualitativas por meio de entrevistas que implicam em um contato face a face pode estar indicando maior preocupação dos autores com a subjetividade e, portanto, com o adolescente enquanto sujeito e não apenas enquanto autor de ato infracional. Por outro lado, o predomínio de pesquisas com adolescentes do sexo masculino em situação de internação faz com que pouco se saiba sobre adolescentes em outras condições, seja de gênero/sexo ou em cumprimento de outras medidas socioeducativas. Sobre as medidas de reparação de danos e semiliberdade não se identificou nenhum artigo, sobre a medida de advertência, um único estudo (Carvalho \& Gomide, 2005) teve um participante. Este cenário revela a importância de pesquisas que abarquem campos e participantes diversificados, visando, inclusive, conhecer o perfil dos(as) adolescentes que cumprem medidas em meio aberto, em particular as medidas de advertência e reparação de danos. Uma questão que se desdobra a partir do presente estudo de revisão é: em quais situações e para quais adolescentes são aplicadas as medidas de advertência e reparação de danos? Uma hipótese seria de que as mesmas são aplicadas aos adolescentes de classe média e alta, que, quando apreendidos, recebem medidas consideradas brandas, ficando as medidas mais severas, como a internação, para os adolescentes pobres.

A seguir, para efeito de síntese analítica, construímos três grupos discursivos que explicam a prática infracional na adolescência. O primeiro remete aos fatores contextuais presentes no dia a dia da vida dos adolescentes que vivem nas periferias, o segundo abarca o histórico da vida dos adolescentes em cumprimento de medida socioeducativa, o terceiro, sem excluir os anteriores, problematizou a dimensão histórico política do fenômeno em questão. Finalizando, assinala-se 
a presença de adolescentes que não cometeram ato infracional, mas se encontram internados no sistema socioeducativo. Importante ressaltar que um mesmo autor pode partilhar com mais de um grupo.

O primeiro grupo discursivo explicou a motivação para a prática infracional por meio dos fatores contextuais, ou seja, aqueles que consideram o entorno imediato da vida dos adolescentes que vivem nas periferias, tais como: facilidade para entrar para o tráfico de drogas, o estilo de vida na comunidade, a influência dos amigos, as relações familiares e escolares problemáticas, o desejo de ter dinheiro para gastar com drogas, festas e mulheres, o desejo de visibilidade, de pertencimento e prestígio (Gomes \& Conceição, 2014; Junqueira \& Jacoby, 2006, I. R. O. Silva \& Salles, 2011). Tais argumentos, inclusive, foram encontrados nos discursos dos próprios adolescentes (I. R. O. Silva \& Salles, 2011).

A história de vida compõe o segundo grupo discursivo e abarca o passado de privações materiais e afetivas, com vivências, às vezes, extremas de violência, inclusive de violência sexual relatada pelas adolescentes. Este grupo compreende o ato infracional como efeito deste histórico agregado à pobreza, à falta de oportunidade e ao imperativo de uma sociedade consumista e imediatista. Vale ressaltar que parte deste discurso foi reportado pelas mães dos adolescentes, em particular a relação entre o ato infracional e a ausência ou conflitos com a figura paterna (Dias et al., 2011).

O terceiro grupo discursivo remete à dimensão histórico política e não exclui os discursos anteriores, mas antes, propõe um giro paradigmático, pois não se atém aos motivadores para a prática infracional, mas como determinada sociedade identifica seus desviantes. Becker (1960/2012), um dos estudiosos sobre como as sociedades identificam seus desviantes defende que não existem dois grandes grupos de pessoas: aquelas que desviam e aquelas que agem em conformidade com todas as regras. $\mathrm{O}$ autor compreende o comportamento desviante enquanto ação coletiva e propõe que se analise a complexa trama de relações estabelecidas entre quatro grupos sociais: 1) desviantes que foram identificados como tal; 2) desviantes que não foram identificados; 3) não desviantes que foram acusados de desvio; 4) e não desviantes de fato. Para o autor, as relações estabelecidas envolvem todos os atores sociais e vão incidir na compreensão do que é desvio, na grande variabilidade de condutas chamadas "desviantes", na continuidade ou ruptura, e até mesmo na identificação ou não do sujeito como desviante.
Misse (1995) desconstrói o argumento de que a criminalidade é causada pela pobreza sob a alegação de que a maioria dos presos é pobre. $\mathrm{O}$ autor argumenta que muitos pobres são trabalhadores e se a prisão é mais frequente neste grupo social se deve ao fato de haver um roteiro policial típico que tende a identificar a criminalidade nos ambientes mais pobres.

O processo de identificação de desviantes pode explicar, ainda que parcialmente, a presença de adolescentes internados sem que tenham cometido nenhum ato infracional (Feitosa \& Boarini, 2014; Maraschin \& Raniere, 2011, Valença \& Castro, 2014). Determinados adolescentes estão de tal modo previamente marcados pela sociedade para serem identificados como criminosos que, mesmo não infracionando, correm o risco de serem internados por um complexo variado de motivos que não encontram categorização na rubrica "ato infracional", como por exemplo, o uso de drogas que, em tese, seria um problema da área da saúde e não da justiça. "[...] a criminalização da infância e da juventude pobre é uma permanência histórica: da catequese dos indiozinhos sem alma aos filhos dos escravos, a Republica não produziu nenhuma ruptura nesse marco social" (Batista, 2009, p. 97).

Historicamente há um estigma sobre os adolescentes pobres e negros. Segundo Goffman (1978) o estigma é qualquer característica que faz com que o seu portador não corresponda ao esperado pela sociedade na qual ele vive. $O$ autor distingue três diferentes tipos de estigmas: as abominações do corpo (deformidades físicas), estigmas tribais de raça, nação e religião e as culpas de caráter individual como as atribuídas a pessoas desonestas, fracas, levadas por paixões associadas às situações de doença mental, prisão, vício, alcoolismo, desemprego etc. É sob esse último tipo de estigma que vivem os adolescentes em conflito com a lei.

Uma vez estigmatizado, o adolescente passa a merecer o tratamento gravoso, violento e desumano. Ao mesmo tempo, esse adolescente pode acreditar que "é um sujeito criminal, isto é, alguém de quem esperamos que sempre continue a cometer crimes" (Misse, 2007, p. 193). Quando os próprios indivíduos frequentemente suspeitos ou acusados incorporam em sua própria identidade essa suspeita e essa acusação, fazem-no como um papel social esperado e como uma carreira a que se pode apegar. No entanto, quando esse papel e essa carreira contaminam todos os demais papéis sociais desse indivíduo, de modo a produzi-lo como um ser anômalo, uma personalidade anormal, um "perigo" para os 
demais, então a incriminação passa a habitar plenamente o sujeito social. A isso tenho chamado de "sujeição criminal", o crime incorporado no sujeito, naturalizado na personalidade do sujeito - que se torna agora um "mau caráter", um "bandido" (Misse, 2007, pp. 192-3).

Neste sentido, fica a seguinte questão: os fatores contextuais presentes no dia a dia da vida dos adolescentes que vivem nas periferias, somados ao histórico de vida permeado por privações e violências, aliados aos desejos de consumo e pertencimento compõem o cenário da prática infracional na adolescência? Ou, os adolescentes que possuem tal perfil e histórico estariam previamente marcados para serem identificados e tratados como marginais? O segundo postulado explicaria a presença no sistema socioeducativo de adolescentes que não cometeram ato infracional, a ausência de adolescentes de classe média/alta, bem como a presença de um adolescente de 11 anos (Zappe \& Ramos, 2010) cumprindo medida de internação, em franco desrespeito ao ECA. Os dispositivos utilizados pela sociedade para identificar, selecionar e marcar como marginais determinados indivíduos são tão importantes para a compreensão da prática infracional quanto os fatores contextuais e de vida dos adolescentes.

\section{Considerações finais}

A expressão "adolescente em conflito com a lei" é polissêmica, despertando inúmeras compreensões e representações sobre quem são estes jovens. São adolescentes muito diferentes entre si, embora a elaboração de um perfil daqueles que se encontram internados possa dar a sensação de que estes dados contemplam a maioria, isso não é verdadeiro.

Além de muito diferentes, praticaram (aqueles que de fato praticaram) atos infracionais distintos. Se os adolescentes são diferentes e os atos por eles praticados também, os motivos para a prática infracional também serão distintos. Além disso, os motivos dependerão de quem os identifica - se o próprio adolescente, seus familiares, o aparato jurídico etc. - e em qual contexto estes motivos estão sendo relatados - se em uma conversa de confidência entre dois adolescentes, diante do juiz etc.

A fragilidade de acesso às políticas públicas de educação, moradia, saúde etc., os limites quanto às perspectivas de futuro somados aos desejos de consumo e pertencimento constituem dimensões importantes da prática infracional na adolescência. Porém, tanto os adolescentes como seus familiares tendem a responsabilizar a si próprios, excluindo a dimensão social e política do fenômeno.

Tais considerações devem ser objeto de atenção e reflexão cotidiana dos profissionais que trabalham com os adolescentes em cumprimento de medida socioeducativa. Primeiramente, existe uma seletividade que atravessa as práticas sociais; a abordagem policial e o próprio sistema judiciário tenderão a eleger quais infratores serão apreendidos e destes, quais deverão compor o sistema socioeducativo. Tal seletividade se ampara no estigma que marca historicamente determinados grupos sociais e corre o risco de ser ratificada por meio dos processos socioeducativos. Foi possível identificar neste estudo, dentre outros achados, a importância das sentenças, relatórios e outros documentos produzidos por profissionais que podem, a depender do seu conteúdo, fixar o adolescente no lugar de marginal reforçando o estigma e a exclusão social. As explicações simplistas que tendem a justificar a prática infracional a partir de características individuais ou familiares devem ser descartadas, e os profissionais devem ter atenção diferenciada para com o conteúdo dos documentos que produzem, pois os mesmos podem servir para reafirmar o estigma, a discriminação e a sujeição criminal.

Ante a difícil tarefa de identificar e generalizar os motivos para a prática infracional na adolescência, talvez deveríamos nos questionar, tal como Becker (1960/2012), como, em um mundo com tantas injustiças e desigualdades, há um número tão pequeno de pessoas que desviam. É significativo que no cenário brasileiro apenas $0,5 \%$ do total dos adolescentes esteja em cumprimento de alguma medida socioeducativa. $\mathrm{E}$, por fim, talvez devêssemos abandonar a ânsia de buscar explicações, de tentar esclarecer os motivos, os por quês dos adolescentes infracionarem, e tentar compreender como tal cenário se configurou enquanto parte de uma história coletiva da nossa sociedade e cultura, transcendendo de uma compreensão da prática infracional individual e personalizada para uma compreensão histórica e coletiva.

\section{Referências}

Bastos, S. S., \& Rabinovich, E. P. (2012). Jovens de classes médias infratores e a questão da autoridade. Estudos e Pesquisas em Psicologia, 12(2), 539-553. Recuperado de http://www.revispsi.uerj. $\mathrm{br} / \mathrm{v} 12 \mathrm{n} 2 /$ sumariov12n2.html

Batista, V. M. (2009) A juventude na criminologia. In H. Bocayuva \& S. A. Nunes (Orgs.), Juventudes, subjetivações e violências (pp. 91-100). Rio de Janeiro: Contra Capa. 
Becker, H. (2012). Outsiders: hacia una sociología de la desviación. Buenos Aires: Siglo Veintiuno Editores. (Obra original publicada em 1960)

Bernardy, C. C. F., \& Oliveira, M. L. F. (2010). O papel das relações familiares na iniciação ao uso de drogas de abuso por jovens institucionalizados. Revista da Escola de Enfermagem, USP, 44(1), 11-17. doi: 10.1590/S0080-62342010000100002

Bocca, M. C. (2009). Ato infracional na adolescência: um fenômeno contemporâneo. Arquivos de Ciências da Saúde da UNIPAR, 13(2), 169-179. doi: 10.25110/arqsaude.v13i2.2009.3021

Botelho, L. L. R., Cunha, C. C. A., \& Macedo, M. (2011). O método da revisão integrativa nos estudos organizacionais. Gestão e Sociedade, 5(11), 121-136. doi: 10.21171/ges.v5i11.1220

Branco, B. M., Wagner, A, \& Demarchi, K. A. (2008). Adolescentes infratores: rede social e funcionamento familiar. Psicologia: Reflexão e Crítica, 21(1), 125-132. doi: 10.1590/S0102-79722008000100016

Brito, L. M. T. (2007). Liberdade assistida no horizonte da doutrina de proteção integral. Psicologia: Teoria e Pesquisa, 23(2), 133-138. doi: 10.1590/S0102-37722007000200003

Carvalho, M. C. N., \& Gomide, P. I. C. (2005). Práticas educativas parentais em famílias de adolescentes em conflito com a lei. Estudos de Psicologia, 22(3), 263-275. doi: 10.1590/ S0103-166X2005000300005

Castro, A. L. S., \& Guareschi, P. (2008). Da privação da dignidade social à privação da liberdade individual. Psicologia \& Sociedade, 20(2), 200-207. doi: 10.1590/S0102-71822008000200007

Conselho Nacional dos Direitos da Criança e do Adolescente. (2006). Sistema Nacional de Atendimento Socioeducativo - SINASE. Brasília, DF. Recuperado de http://www.condeca.sp.gov.br/legislacao/sinase_integra.pdf

Conte, M., Henn, R. C., Oliveira, C. S., \& Wolff, M. P. (2008). "Passes" e impasses: adolescência - drogas - lei. Revista Latinoamericana de Psicopatologia Fundamental, 11(4), 602-615. doi: 10.1590/ S1415-47142008000400007

Decreto n. 3.597 (2000, 12 de setembro). Promulga a convenção 182 e a recomendação 190 da organização internacional do trabalho (OIT) sobre a proibição das piores formas de trabalho infantil e a ação imediata para sua eliminação, concluídas em Genebra, em 17 de junho de 1999. Brasília, DF: Presidência da República.

Dell'Aglio, D., Benetti, S., Deretti, L., D'Incao, D., \& Leon, J. (2005). Eventos estressores no desenvolvimento de meninas adolescentes cumprindo medidas sócio-educativas. Paidéla, 15(30), 119-129. doi: 10.1590/S0103-863X2005000100013

Dias, A. C. G., Arpini, D. M., \& Simon, B. R. (2011). Um olhar sobre a família de jovens que cumprem medidas socioeducativas. Psicologia \& Sociedade, 23(3), 526-535. doi: 10.1590/ S0102-71822011000300010

Feitosa, J. B., \& Boarini, M. L. (2014). The defense of socio-educational internment: Feature of the hygienist principles. Paidéia, 24(57), 125133. doi: $10.1590 / 1982-43272457201415$

Ferreira, S. L. (2007). Estudo comparativo sobre o adolescente autor de ato infracional no centro (Estados Unidos da América) e na periferia (Brasil) do capitalismo. Revista Urutágua - Revista Acadêmica Multidisciplinar, 14. Recuperado de http://www.urutagua.uem. br/014/14ferreira.PDF

Formiga, N. S. (2010). Pares socionormativos e condutas desviantes: testagem de um modelo teórico. Barbarói, 32(1), 28-43. doi: 10.17058/barbaroi.v0i0.998
Francisco, J. C., \& Martins, M. F. (2014). Adolescentes em privação de liberdade na Fundação Casa - Sorocaba, SP: ato infracional e processo educativo. Série-Estudos, 38, 183-201. Recuperado de http:// www.serie-estudos.ucdb.br/index.php/serie-estudos/article/view/741

Gallo, A. E., \& Williams, L. C. A. (2008). A escola como fator de proteção à conduta infracional de adolescentes. Cadernos de Pesquisa, 38(133), 41-59. doi: 10.1590/S0100-15742008000100003

Goffman, E. (1978). Estigma: notas sobre a manipulação da identidade deteriorada. Rio de Janeiro: Zahar Editores.

Gomes, C. C., \& Conceição, M. I. G. (2014). Sentidos da trajetória de vida para adolescentes em medida de liberdade assistida. Psicologia em Estudo, 19(1), 47-58. doi: 10.1590/1413-7372189590005

Huculak, S., McLennan, J. D., \& Bordin, I. A. S. (2011). Exposure to violence in incarcerated youth from the city of São Paulo. Revista Brasileira de Psiquiatria, 33(3), 314-320. doi: 10.1590/ S1516-44462011000300011

Junqueira, M. R., \& Jacoby, M. (2006). O olhar dos adolescentes em conflito com a lei sobre o contexto social. Revista Textos \& Contextos, 6(2), 1-18. Recuperado de http://revistaseletronicas. pucrs.br/ojs/index.php/fass/article/view/1036

Lazzarotto, G. D. R. (2014). Medidas socioeducativas: cartas ao reinado do saber. Psicologia em Estudo, 19(3), 503-514. doi: 10.1590/1413-73725000313

Lei n. 8.069, de 13 de julho de 1990. (1990, 13 de julho). Dispõe sobre o Estatuto da Criança e do Adolescente. Diário Oficial da União, seção 1.

Lima, I. M. S. O., Alcântara, M. A. R., Almeida, K. V. D., \& Alves, V. S. (2006). Experiências de violência intrafamiliar entre adolescentes em conflito com a lei. Revista Brasileira de Crescimento e Desenvolvimento Humano, 16(2), 16-24. Recuperado de http://pepsic.bvsalud.org/scielo.php?script=sci_arttext\&pi$\mathrm{d}=$ S0104-12822006000200003\&lng=pt\&tlng=pt.

Lühring, G., Gauer, G., Vasconcellos, S., Davóglio, T., Silva, L., \& Navarrette, S. S. (2014). Correlação entre traços de psicopatia e abuso de drogas em uma amostra de adolescentes brasileiros em conflito com a lei. Revista Saúde e Desenvolvimento Humano, 2(1), 29-39. doi: 10.18316/1226

Maraschin, C., \& Raniere, E. (2011). Socioeducação e identidade: onde se utiliza Foucault e Varela para pensar o Sinase. Revista Katálysis, 14(1), 95-103. Recuperado de

https://periodicos.ufsc.br/index.php/katalysis/article/view/ S1414-49802011000100012/17723

Martins, M. C., \& Pillon, S. C. (2008). A relação entre a iniciação do uso de drogas e o primeiro ato infracional entre os adolescentes em conflito com a lei. Cadernos de Saúde Pública, 24(5), 1112-1120. doi: 10.1590/S0102-311X2008000500018

Ministério dos Direitos Humanos. (2012). Secretaria Especial de Direitos Humanos. Socioeducativo ao Adolescente em Conflito com a lei. Brasília, DF: Secretaria Especial de Direitos Humanos.

Ministério dos Direitos Humanos. (2017). Secretaria Nacional dos Direitos da Criança e do Adolescente. Levantamento anual SINASE 2014. Brasília (DF): Secretaria Nacional dos Direitos da Criança e do Adolescente.

Misse, M. (1995). Cinco teses equivocadas sobre a criminalidade urbana no Brasil. Violência e Participação Política no Rio de Janeiro/ Série Estudos, 91, 23-39. Rio de Janeiro: IUPERJ.

Misse, M. (2007). Notas sobre a sujeição criminal de crianças e adolescentes. In J. Sento-Sé Trajano \& V. Paiva (Orgs.), Jovens em conflito com a lei (pp. 191-200). Rio de Janeiro: Garamond. 
Moreira, L. E., \& Toneli, M. J. F. (2014). Paternidade, família e criminalidade: uma arqueologia entre o Direito e a Psicologia. Psicologia \& Sociedade, 26(n. spe), 36-46. doi: 10.1590/S0102 71822014000500005

Muller, F., Barbosa, P. S., Oliveira, C. C., Santos, R. G., \& Paludo, S. S. (2009). Perspectivas de adolescentes em conflito com a lei sobre o delito, a medida de internação e as expectativas futuras. Revista Brasileira Adolescência e Conflitualidade, 1(1), 70-87. doi: 10.17921/2176-5626.n1p\%25p

Nardi, F. L., \& Dell'Áglio, D. D. (2012). Adolescentes em conflito com a lei: percepções sobre a família. Psicologia: Teoria e Pesquisa, 28(2), 181-191. doi: 10.1590/S0102-37722012000200006

Oliveira Sobrinho, A. S. (2013). São Paulo e a ideologia higienista entre os séculos XIX e XX: a utopia da civilidade. Sociologias, 15(32), 210-235. doi: 10.1590/S1517-45222013000100009

Pereira, S. E. F. N., \& Sudbrack, M. F. O. (2008). Drogadição e atos infracionais na voz do adolescente em conflito com a lei. Psicologia: Teoria e Pesquisa, 24(2), 151-159. doi: 10.1590/ S0102-37722008000200004

Priuli, R. M. A., \& Moraes, M. S. (2007). Adolescentes em conflito com a lei. Ciência e Saúde Coletiva, 12(5), 1185-1192. doi: 10.1590/ S1413-81232007000500015

Schmitt, R., Pinto, T. P., Gomes, K. M., Quevedo, J., \& Stein, A. (2006). Personalidade psicopática em uma amostra de adolescentes infratores brasileiros. Revista de Psiquiatria Clínica, 33(6), 297-303. doi: 10.1590/S0101-60832006000600002

Silva, M. M. C. (2007). A produção da delinquência juvenil: uma análise sociológica da aplicação das medidas socioeducativas a adolescentes em conflito com a lei no Município de Nova Iguaçu, RJ. Revista de Sociologia Jurídica, 4, 1-26.

Silva, M. M. C. (2009). Buscando boas meninas: um estudo das justificações dadas por adolescentes que infringiram as leis. Confluências. Revista Interdisciplinar da Sociologia e do Direito, 11(2), 91-112. doi: 10.22409/conflu11i2.p216

Silva, I. R. O., \& Salles, L. M. F. (2011). Adolescente em liberdade assistida e a escola. Estudos de Psicologia, 28(3), 353-362. doi: 10.1590/S0103-166X2011000300007
Souza, E. M., Silva-Abrão, F. P., \& Oliveira-Almeida, J. (2011). Desigualdade social, delinquência e depressão: um estudo com adolescentes em conflito com a lei. Revista de Salud Pública, 13(1), 13-26. Recuperado de http://www.scielosp.org/pdf/rsap/v13n1/ v13n1a02.pdf

Spagnol, A. S. (2005). Jovens delinquentes paulistanos. Tempo Social, 17(2), 272-299. doi: 10.1590/S0103-20702005000200012

Supremo Tribunal de Justiça. Súmula 492, Terceira Seção, julgado em 08/08/2012, DJe 13/08/2012. Recuperado de https://jus.com.br/ artigos/22631/comentarios-iniciais-a-sumula-492-do-stj-adolescentes-e-internacao-no-trafico-de-drogas

Valença, M. A., \& Castro, H. R. C. (2014). Carreira de indisciplinas em julgamento: o uso de drogas como elemento justificador da aplicação de medida socioeducativa de internação no Distrito Federal. Revista Eletrônica da Faculdade de Direito - PUCRS, 6(2), 305318. doi: 10.15448/2177-6784.2014.2.18602

Vorcaro, A., Mazzini, C. A., \& Monteiro, J. P. (2008). Ato infracional e metáfora

paterna. Psicologia: Teoria e Prática, 10(2), 135-146. Recuperado de http://pepsic.bvsalud.org/scielo.php?script=sci_arttext\&pi$\mathrm{d}=$ S1516-36872008000200011\&lng=pt\&nrm=iso\&tlng=pt

Zappe, J. G., \& Dias, A. C. G. (2010). Delinquência juvenil na produção científica nacional: distâncias entre achados científicos e intervenções concretas. Barbarói, 33(2), 82-103. doi: 10.17058/barbaroi. v0i0.1503

Zappe, J. G., \& Dias, A. C. G. (2012a). Violência e fragilidades nas relações familiares: refletindo sobre a situação de adolescentes em conflito com a lei. Estudos de Psicologia, 17(3), 389-395. doi: 10.1590/S1413-294X2012000300006

Zappe, J. G., \& Dias, A. C. G. (2012b). Adolescência, violência e uso de drogas: um estudo de casos múltiplos. Adolescência \& Saúde, 9(2), 30-36. Recuperado de http://www.adolescenciaesaude.com/ detalhe_artigo.asp?id=313

Zappe, J. G., \& Ramos, N. V. (2010). Perfil de adolescentes privados de liberdade em Santa Maria/RS. Psicologia \& Sociedade, 22(2), 365-373. doi: 10.1590/S0102-71822010000200017

1. Classificação disponível em http://www.capes.gov.br/avaliacao/instrumentos-de-apoio/tabela-de-areas-do-conhecimento-avaliacao.

Luciene Jimenez, Doutora em Saúde Pública pela Universidade de São Paulo, é Docente da Universidade Anhanguera de São Paulo (UNIAN). Endereço para correspondência: Rua Diogo Freire, 281, Jardim da Saúde, SP. CEP: 04148-010. Telefone para contato:

(11) 97631.8851. E-mail: lucienejimenez@hotmail.com

Vanda Regina Marques, Especialista em Gerontologia Social (SBGG), é Diretora de Departamento de Trabalho Social da Prefeitura do Município de Diadema (SP). E-mail: van_alschefsky@hotmail.com

Recebido em 09.Nov.15 Revisado em 07.Mar.18 Aceito em 10.Out.18 